Caligrama, Belo Horizonte, v. 23, n. 2, p. 75-98, 2018

(c)

\title{
Denominações do eclesiástico católico no português das Minas Gerais setecentistas
}

\section{Study on the titles given to Catholic clergyman in Minas Gerais in the 18th century}

\author{
Marcus Vinícius Pereira das Dores \\ Universidade Federal de Minas Gerais, Belo Horizonte, Minas Gerais / Brasil \\ $\mathrm{CNPq}$ \\ marcusdores@gmail.com \\ Aléxia Teles Duchowny \\ Universidade Federal de Minas Gerais, Belo Horizonte, Minas Gerais / Brasil \\ alexiaduchowny@gmail.com
}

Resumo: O principal objetivo deste trabalho é apresentar os resultados de um estudo sobre os itens lexicais utilizados para se fazer referência ao religioso ordenado católico, isto é, capelão, clérigo, cura, padre, pároco, sacerdote e vigário, no português setecentista das Minas Gerais, Brasil. Como base de pesquisa, utilizaram-se três tipos de obras lexicográficas: duas obras coetâneas ao corpus (BLUTEAU, 1728; SILVA, 1813); dois dicionários etimológicos (BUENO, 1974; CUNHA, 1986), e uma obra contemporânea (HOUAISS, 2009).

Palavras-chave: português setecentista; história das palavras; etimologia; lexicografia; eclesiástico católico.

Abstract: The main objective of this work is to present the results of a study on the lexical items used to refer to the Catholic religious leaders, i.e. capelão, clérigo, cura, padre, pároco, sacerdote e vigário, in the 18th century Portuguese of Minas Gerais, Brazil. As a research base, we used three types of lexicographic works: two of them contemporaneous with the corpus (BLUTEAU, 1728; SILVA, 1813); two etymological dictionaries (BUENO, 1974; CUNHA, 1986); and a contemporary work (HOUAISS, 2009).

Keywords: 17th century Portuguese; history of words; etymology; lexicography; catholic clergyman. 


\section{Introdução}

Baseando-se em algumas obras lexicográficas, neste artigo, buscaremos levantar informações sobre os itens lexicais utilizados para denominar o religioso ordenado em segundo grau ${ }^{1}$ da Igreja Católica, na língua portuguesa do século XVIII. Salviano (2016, p.79) afirma que a "definição histórico-etimológica de um lexema não se dá por meio de uma trajetória linear e evidente", o que será corroborado por nossas investigações. Viaro (2011, p.98) também alerta que, "[p]ara se chegar a um bom étimo, não basta, como pensam muitos, apenas ter imaginação e conhecimento de sua língua materna ou de apenas algumas línguas". Assim, não nos apoiaremos no senso comum ou em suposições, mas, sim, na metodologia proposta por Viaro (2011). Em virtude do limite de caracteres estabelecido e da extensão das definições dos itens lexicais descritos, não nos aprofundaremos nas teorias dos estudos do léxico. Nesse sentido, nosso trabalho assume um caráter mais descritivo.

Como todas as palavras aqui descritas possuem um referente muito próximo, o de um religioso ordenado católico, outro objetivo deste trabalho é verificar qual seria a proximidade semântica entre os itens, a ser analisada nas obras consultadas. Não são muitos os trabalhos que possuem objetivos como os nossos e, sobre isso, Malkiel (1996, p.155163) elenca vários fatores que favorecem a baixa ocorrência de estudos na área da etimologia. Alguns deles: predomínio de estudos sincrônicos, de um modo geral; a ausência de teoria bem embasada; a perda do prestígio desses estudos; o alto grau de subjetividade na área; a consciência da complexidade das inter-relações quando do aparecimento de um lexema; a necessidade de um olhar crítico a toda análise etimológica anterior, entre outros. Dos trabalhos que se dedicam à descrição do léxico religioso, vale destacar o de Hallig e Wartburg (1963), no qual os autores sistematizam, por meio do sistema racional de conceitos, a teoria dos campos linguísticos proposta por Trier (1931). ${ }^{2}$

\footnotetext{
${ }^{1}$ O Catecismo da Igreja Católica, na sua versão impressa de 1993, Artigo 6, aponta: "A Ordem é o sacramento graças ao qual a missão confiada por Cristo aos Apóstolos

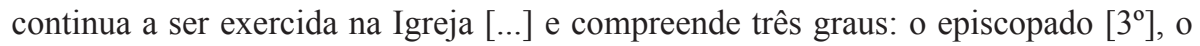
presbiterado $\left[2^{\circ}\right]$ e o diaconato $\left[1^{\circ}\right]^{\prime \prime}$.

${ }^{2}$ Apesar de nossos esforços, não foi possível ter acesso a esses estudos. Agradecemos ao parecerista que nos fez as indicações.
} 
As palavras selecionadas para este trabalho foram extraídas de dois corpora. O primeiro deles foi o grupo de inventários, do século XVIII, que integra o inédito Livro de inventários da Catedral de Mariana (1749 - 1904), da cidade de Mariana, Minas Gerais, cuja edição e glossário encontram-se em andamento. ${ }^{3} \mathrm{O}$ segundo, a obra Edição semidiplomática e fac-similar de documentos adamantinos setecentistas (2013), organizada por Sueli Maria Coelho e Aléxia Teles Duchowny, constitui um conjunto dos estatutos e compromissos de irmandades, também do século XVIII, da cidade de Diamantina, Minas Gerais, sendo eles: o Estatuto da Ordem Terceira de São Francisco (1778), o Livro de compromisso da Irmandade de Nossa Senhora das Mercês (1778), o Livro de compromisso da Irmandade de Nossa Senhora do Amparo (1782) e o Compromisso da Irmandade do Santíssimo Sacramento (1783).

Para se alcançar os objetivos propostos, consultaremos as palavras encontradas no corpus selecionado nas seguintes obras lexicológicas, seguidas dos nomes simplificados empregados por nós: i) Vocabulario portuguez \& latino, do padre Raphael Bluteau (1712-1728); ii) Diccionario da lingua portugueza, de Moraes Silva (1813); iii) Grande dicionário etimológico-prosódico da língua portuguesa, de Silveira Bueno (1974); iv) Dicionário etimológico da língua portuguesa, coordenado por Geraldo da Cunha (2010); v) Dicionário eletrônico Houaiss da língua portuguesa, de Antônio Houaiss (2009).

Viaro $(2011 ; 2017)$ discute diferentes questões relacionadas aos estudos etimológicos. Sua principal divisa é que não se pode trabalhar com etimologia sem embasamento de textos pretéritos. Muitas vezes, a etimologia das palavras é tratada por alguns meios, acadêmicos ou não, de forma muito imprudente. Um exemplo clássico é o mito que permeia a palavra aluno nos estudos voltados para educação. Alguns profissionais da área se recusam a utilizar esse item lexical, justificando que tal uso apontaria para uma postura conservadora, já que a palavra seria formada pela junção do prefixo de negação "a-" e a base "lumni", que significa luz. Na verdade, a palavra portuguesa aluno deriva do latim alumnus, que significa: "criança de peito, pupilo, discípulo" (TORRINHA, 1942, p.47).

Esse exemplo de uma falsa etimologia empregada para a palavra "aluno" - aquele que é sem luz - ratifica a ideia de Viaro (2011, p.97)

\footnotetext{
${ }^{3}$ Pesquisa de mestrado desenvolvida por Marcus Vinícius Pereira das Dores, no Programa de Pós-Graduação em Estudos Linguísticos da Universidade Federal de Minas Gerais.
} 
de que "[e]timologia e imaginação [...] nem sempre fazem um bom casamento". Toda pesquisa etimológica precisa ter como pano de fundo critérios muito claros e específicos. Ainda assim, diversas dúvidas podem não ser sanadas. Viaro (2011.p.97) ainda completa: “[n]ão se deve confiar num etimólogo que ofereça um étimo qualquer com certeza absoluta, pois tal atitude seria típica da Religião e não da Ciência”.

Pensando nas palavras aqui estudadas (capelão, clérigo, cura, padre, pároco, sacerdote e vigário) e no rigor dos estudos etimológicos, nos deparamos com o problema da impossibilidade de se confiar nos termini a quo de dicionários como o Houaiss (cf. VIARO, 2017). A etimologia fornecida por esse dicionário é baseada principalmente nas obras de José Pedro Machado - que traz datas vagas para a ocorrência de algumas palavras - e de Antônio Geraldo da Cunha - que apresenta datações mais precisas (Cf. VIARO, 2011, p.106-109). Esperamos que, com o uso de várias obras, o problema seja diminuído.

Seabra (2004, p.22), ao reconhecer que "o ato de criar ou substituir as palavras ao longo do tempo e o seu eventual desdobramento em novas palavras são fenômenos, entre muitos outros fenômenos linguísticos, mais abertamente expostos à observação humana", dialoga diretamente com o assunto que abordamos neste trabalho. A figura masculina investida de autoridade religiosa, em diferentes textos e épocas, é nomeada por diferentes itens lexicais que carregam traços singulares do referente.

Ao tratar da etimologia, Seabra (2004, p.220) afirma que

Fernão de Oliveira ${ }^{4}$ discute o quanto é complexo o estudo da etimologia, assinalando que é extremamente difícil motivar a origem de cada nome, pois seria preciso saber de onde surgiram as "coisas" correspondentes e, em cada caso, chegar até a "pessoa particular" que impôs tal nome.

Justamente por isso, os estudos etimológicos devem ser sempre pautados em corpora confiáveis que tenham sido criados com finalidade de servir aos estudos linguísticos.

Segundo Silva, Xavier e Paula (2016, p.56), “[s]abe-se que na hierarquia católica o maior cargo é ocupado pelo Papa, responsável por nomear os cardeais e bispos. Posteriormente, vêm arrolados o cardeal,

\footnotetext{
${ }^{4}$ OLIVEIRA, F. de. Gramática da linguagem portuguesa. Lisboa: Academia de Ciências Humanas, 2000. A $1^{\mathrm{a}}$ edição é de 1536.
} 
o bispo, o arcebispo, pároco, o diácono, o seminarista, o coroinha, entre outros que ocupam posições secundárias".

A seguir, faremos uma breve descrição das cinco obras lexicográficas consultadas para a elaboração deste trabalho.

\section{Obras consultadas}

\subsection{Vocabulario portuguez \& latino (1728)}

O Vocabulario de Bluteau é conhecido por ser um marco da produção lexicográfica em português, sendo o primeiro a fixar um corpus autorizado nessa língua. Como qualquer produção lexicográfica baseada em corpus, Bluteau deixou incutido na sua obra fortes marcas da sua doutrina (católica) e do pensamento dos seus contemporâneos. Murakawa (2007, p.168), analisando as entradas lexicais da obra de Bluteau, assevera que "[s]uas definições lexicográficas são, por vezes, extensas e detalhadas, abrangendo não só a explicação de uma palavra e a relação de seus sinônimos, mas também pormenores descritivos e históricos" e ainda completa "Bluteau procurou ser o mais abrangente possível em seu trabalho lexicográfico, chegando à exaustão, e algumas vezes a detalhes desnecessários [...]" (MURAKAWA, 2007, p.184). Esse detalhamento e essa extensão, muitas vezes exaustiva, poderão ser percebidos nas definições dos itens analisados neste trabalho.

A versão do Vocabulario que consultamos para este trabalho encontra-se disponível no acervo digital da Biblioteca Brasiliana Guita e José Mindlin. Na transcrição das definições, com exceção da quebra de linha, procuramos deixar os textos fiéis ao que consta no original.

\subsection{Diccionario da lingua portuguesa (1813)}

O Diccionario da lingua portuguesa foi publicado, por Antônio de Morais Silva em 1798 e reeditado por ele em 1813. Conforme Morais Silva aponta no frontispício da sua obra de 1798, trata-se de um trabalho de reformulação e acréscimo do que foi publicado por Bluteau: "Diccionario da Lingua Portuguesa composto pelo Padre D. Rafael Bluteau, reformado, e accrescentado por Antonio de Morais Silva natural do Rio de Janeiro" (SILVA, 1798, p.1). Sobre a obra de Morais Silva, Murakawa (2006, p.61) alega que "[m]uito embora tenha 
utilizado o Vocabulario Portuguez e Latino (1712-1728) de Bluteau como fonte de referência para a elaboração de seu dicionário, apresentou inovações lexicográficas que tornaram sua obra modelo para a produção dicionarística nos séculos seguintes".

A consulta ao Diccionario da lingua portuguesa também foi realizada via acervo digital da Biblioteca Brasiliana Guita e José Mindlin. A transcrição das definições, assim como as do Vocabulario de Bluteau, respeitou ao máximo a forma do texto original.

\subsection{Grande dicionário etimológico-prosódico da língua portuguesa (1974)}

É imprescindível para este trabalho de averiguação etimológica a consulta em obras que tentem apresentar alguns apontamentos etimológicos e possíveis datações dos itens aqui analisados. O Grande dicionário etimológico-prosódico da língua portuguesa, publicado por Francisco da Silveira Bueno, embora não traga as datações das palavras que pesquisamos, nos auxiliou com as definições, das quais extraímos alguns itens lexicais afins da palavra entrada. Além das informações etimológicas, o autor apresenta pelo menos uma definição para cada item.

\subsection{Dicionário etimológico da língua portuguesa (2010)}

Para tornar este trabalho um pouco mais completo, resolvemos consultar também o Dicionário etimológico da língua portuguesa, de Antônio Geraldo da Cunha, que traz, segundo Santana (2011, p.141), citando Dapena (2002),

[...] ao longo da estrutura de seu dicionário, as palavras alfabeticamente e por famílias etimológicas, sendo que esta última distribuição "consiste en la agrupación en torno a una raíz, étimo o palabra inicial en una derivación, de todos los vocablos emparentados" (DAPENA, 2002, p.73) $)^{5}$ e, com isso, ele opta por apresentar as palavras que são cognatas "num único verbete".

Contudo, esse dicionário traz pouquíssimas definições dos itens que o compõe. O que nos impossibilitaria, para este trabalho, usá-lo como

\footnotetext{
${ }^{5}$ Tradução nossa: "consiste no agrupamento em torno de uma raiz, étimo ou palavra inicial em uma derivação, de todas as palavras relacionadas".
} 
única fonte de pesquisa. Sobretudo, porque nosso objetivo perpassa pelo cotejo das informações encontradas em diferentes obras lexicográficas.

\subsection{Dicionário Houaiss da Língua Portuguesa (2009)}

Optamos por selecionar um dicionário contemporâneo para também compor o conjunto de obras de consulta deste trabalho. A escolha pelo Dicionário eletrônico Houaiss da Língua Portuguesa se deu pelo fato de ele ser digital, o que facilita a atualização dos dados. Ainda assim, como aponta Viaro (2017), o Dicionário Houaiss, como outros, possui problemas referentes às informações etimológicas (embora o Houaiss não seja um dicionário etimológico) e ao terminus a quo dos itens lexicais ali presentes. Vale ressaltar ainda que o Dicionário Houaiss é o único, entre os que foram consultados, a apresentar considerações acerca da variação regional do português brasileiro.

Após essa pequena descrição dos materiais consultados, na próxima seção, apresentamos, para cada item lexical - capelão, clérigo, cura, padre, pároco, sacerdote e vigário - que aqui vamos analisar, uma ficha com as seguintes informações: i) obra consultada; ii) definição encontrada (com ênfase nas acepções relacionadas à religião); iii) etimologia; e itens lexicais afins (itens de significado próximo, que coocorrem, nas definições, com os itens pesquisados). As fichas, por sua vez, foram preenchidas com as informações coletadas nas obras lexicográficas, citadas anteriormente.

\section{Descrição dos dados}

Foram encontrados os seguintes termos ${ }^{6}$ no corpus selecionado:

\footnotetext{
${ }^{6}$ Arrolamos 136 ocorrências do termo ministro, uma única ocorrência de subdiáconos e uma de prelado, que não constarão em nossa análise, pois não representam religiosos ordenados em segundo grau.
} 
Tabela 1 - Termos referentes ao religioso ordenado católico no português das Minas Gerais setecentistas

\begin{tabular}{c|c|c|c}
\hline Termo & $\begin{array}{c}\text { Estatutos e } \\
\text { compromissos }\end{array}$ & Livro de inventários & Total \\
\hline Padre & 65 & 31 & 96 \\
Vigário & 49 & 0 & 49 \\
Capelão & 39 & 4 & 43 \\
Sacerdote & 16 & 5 & 21 \\
Pároco & 15 & 6 & 21 \\
Clérigo & 4 & 0 & 4 \\
Cura & 0 & 2 & 2 \\
\hline
\end{tabular}

Nos documentos consultados, a ortografia e a acentuação dos itens distribuídos na Tabela 1 variam bastante, e.g. capelão $\sim$ capela õ $\sim$ capellão $\sim$ capella õ $\sim$ cappelão $\sim$ capelam $\sim$ capellam. Como não afetariam as análises e os resultados de nossa pesquisa, esses casos não foram assinalados, mas fizeram parte do cômputo total de dados.

A seguir, apresentaremos as informações sobre os termos, organizadas em fichas, na ordem do item mais frequente para o menos.

\subsection{Padre}

A palavra padre nos parece ser a mais usual atualmente, no português brasileiro, assim como no século XVIII. Contudo, a sua etimologia se confunde com a etimologia da palavra pai, o que pode gerar imprecisões cronológicas. Em galego e em castelhano, além do mais, a palavra para pai é padre ${ }^{7}$. No entanto, ao nosso ver, a falta de clareza se justifica quando o padre é visto como uma espécie de pai que educa (catequiza) os seus filhos (os fiéis). O Papa, por exemplo, é considerado por muitos fiéis o pai da Igreja Católica.

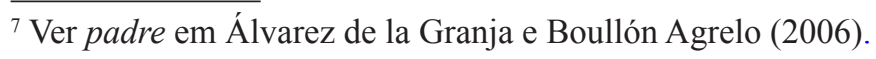


Quadro 1 - Ficha do item lexical padre

\begin{tabular}{|c|c|c|c|}
\hline Obra & Definição & Etimologia & $\begin{array}{c}\text { Itens lexicais } \\
\text { afins }\end{array}$ \\
\hline $\begin{array}{l}\text { BLUTEAU } \\
(1728, \text { p.77, } \\
\text { v. } 6)\end{array}$ & $\begin{array}{l}\text { Deos Padre. A primeira Pessoa da } \\
\text { Santissima Trindade. Deus Pate. } \\
\text { Hum Padre nosso, he a oração } \\
\text { Dominical, porque começa por Pater } \\
\text { noster, \&c. Os Padres da Igreja saõ } \\
\text { os antigos Prelados, e Doutores della. } \\
\text { S. João Chrysostomo, S. Basilio, \&c. } \\
\text { saõ Padres Gregos, S. Agostinho, } \\
\text { S. Ambrosio, são Padres Latinos. } \\
\text { A Biblioteca dos Padres, he hum } \\
\text { ajuntamento das obras de muitos } \\
\text { antigos Padres, q̃ hoje anda impresso } \\
\text { em vinte e sete grandes volumes } \\
\text { de folha. Bibliotheca Sanctorum } \\
\text { Patrum. O Santo Padre. He nome } \\
\text { que os Catholicos daõ ao Papa. (Ser } \\
\text { dispensado pelo Santo Padre. Mon. } \\
\text { Lusitan. tom. 4. 206. col 2.). Padre } \\
\text { espiritual. He o Confessor. Padre se } \\
\text { chamão os Sacerdotes de todas as } \\
\text { Ordens Religiosas, e Congregações } \\
\text { Regulares. Os Padres Carmelitas, } \\
\text { Agostininho, \&c. os Padres da } \\
\text { Trindade, da Companhia, do Oratorio. }\end{array}$ & Não apresenta. & $\begin{array}{l}\text { Prelado, confessor, } \\
\text { sacerdote. }\end{array}$ \\
\hline $\begin{array}{l}\text { SILVA } \\
(1813)\end{array}$ & $\begin{array}{l}\text { Pádre, s. m. por pai. "Padre nosso, } \\
\text { que estás nos Ceos." § Os Padres da } \\
\text { Igreja; os Santos Doutores antigos } \\
\text { della. § Padre Santo: o Papa. § } \\
\text { Sacerdote secular, ou regular. § Padres } \\
\text { Conscriptos: os Senadores Romanos. } \\
\text { Vascone. § Padre espiritual: Director } \\
\text { da consciencia. }\end{array}$ & Não apresenta. & $\begin{array}{l}\text { Pai, santo doutor, papa, } \\
\text { sacerdote secular ou } \\
\text { regular, diretor da } \\
\text { consciência. }\end{array}$ \\
\hline
\end{tabular}


(Conclusão)

\begin{tabular}{|c|c|c|c|}
\hline $\begin{array}{l}\text { BUENO } \\
(1974, \\
\text { p. } 2820-2821)\end{array}$ & $\begin{array}{l}\text { Na língua arcaica e nos primeiros } \\
\text { clássicos tinha o mesmo significado } \\
\text { de pai, sendo a penúltima forma da } \\
\text { cadeia fonética. Fixou-se depois na } \\
\text { significação de sacerdote católico. } \\
\text { Padre-mestre: Padre professor } \\
\text { nas ordens religiosas e também } \\
\text { o mestre espiritual, o diretor dos } \\
\text { noviços. Em muitos colégios } \\
\text { o padre-mestre é o diretor da } \\
\text { disciplina. Padre Santo: O Papa. } \\
\text { Diz-se mais comumente o Santo } \\
\text { Padre. Padres da Igreja: São os } \\
\text { doutores da Igreja, os grandes } \\
\text { intérpretes da doutrina católica. }\end{array}$ & Lat. patrem. & $\begin{array}{l}\text { Pai, sacerdote cató- } \\
\text { lico, mestre espiri- } \\
\text { tual. }\end{array}$ \\
\hline $\begin{array}{l}\text { CUNHA } \\
(2010 \\
\text { p.469) }\end{array}$ & Pai. & $\begin{array}{l}\text { Do latim pater, } \\
\text { patris (lat. patre- } \\
>\text { port. padre } \\
>\text { *pade }>\text { pae } \\
>\text { pai). Padre, } \\
\text { século XIII. }\end{array}$ & Pai. \\
\hline $\begin{array}{l}\text { HOUAISS } \\
(2009)\end{array}$ & $\begin{array}{l}\text { Substantivo masculino. } 1 \text { Homem que } \\
\text { recebeu ordenação sacerdotal; sacer- } \\
\text { dote secular ou regular; } 2 \text { Diacronis- } \\
\text { mo: antigo. m. q. pai ('homem'). }\end{array}$ & $\begin{array}{l}\text { Datação: século } \\
\text { XIII. Do latim, } \\
\text { páter, pátris. }\end{array}$ & $\begin{array}{l}\text { Sacerdote secular ou } \\
\text { regular. }\end{array}$ \\
\hline
\end{tabular}

\subsection{Vigário}

Com base nos dados arrolados, o vigário seria um substituto do prelado ou do pároco. No entanto, o termo parece se confundir com o religioso por ele substituído. 
Quadro 2-Ficha do item lexical vigário

\begin{tabular}{|c|c|c|c|}
\hline Obra & Definição & Etimologia & $\begin{array}{c}\text { Itens lexicais } \\
\text { afins }\end{array}$ \\
\hline $\begin{array}{l}\text { BLUTEAU } \\
(1728, \text { p. } 485 \\
\text { v. } 8)\end{array}$ & $\begin{array}{l}\text { Vigairo, ou Vigario, ou Vicario. } \\
\text { que faz as vezes, et funçoens do } \\
\text { Prelado na sua ausência. } \\
\text { Vigairo do Papa. Antigamente o que } \\
\text { possuhia esta dignidade, só era Bispo. } \\
\text { Depois do Pontificado de Julio IV não } \\
\text { se deu este lugar senão a Cardeaes. O } \\
\text { Vigario do papa tem jurisdição nos } \\
\text { Sacerdotes Seculares, et Regulares, } \\
\text { et nos que tem commettido algum } \\
\text { delicto cõtra a Igreja. } \\
\text { Vigairo, Cura d'almas. Vid. Cura. }\end{array}$ & Vicarius, ii. & $\begin{array}{l}\text { Prelado, vigário } \\
\text { do papa, cura. }\end{array}$ \\
\hline $\begin{array}{l}\text { SILVA } \\
(1813)\end{array}$ & $\begin{array}{l}\text { Vigário, s.m. O Cura d'almas. O } \\
\text { que faz as vezes do prelado. V. g. } \\
\text { vigário geral, do Bispado, da Vara. } \\
\text { [...] }\end{array}$ & Não apresenta. & $\begin{array}{l}\text { Cura d'almas; } \\
\text { prelado. }\end{array}$ \\
\hline $\begin{array}{l}\text { BUENO } \\
(1974, \\
\text { p.4251) }\end{array}$ & $\begin{array}{l}\text { Vigário - s. m. No Brasil, o } \\
\text { mesmo que pároco, o responsável } \\
\text { pelo andamento espiritual de uma } \\
\text { paróquia. Em face do Direito } \\
\text { Canônico, vicarius, vigário, é o } \\
\text { padre que faz as vezes do pároco, } \\
\text { o coadjutor da paróquia, e não o } \\
\text { próprio pároco. O termo já tomou } \\
\text { tal significação em nossa pátria que } \\
\text { a própria Igreja assim o considera. }\end{array}$ & Vicarius. & Pároco. \\
\hline $\begin{array}{l}\text { CUNHA } \\
(2010, \text { p.677) }\end{array}$ & $\begin{array}{l}\text { Vigário sm. 'orig. vicário' 'ext. } \\
\text { padre que faz as vezes do prelado, } \\
\text { ou que substitui o pároco' XIII. }\end{array}$ & Do lat. vicarius. & $\begin{array}{l}\text { Vicário, prelado, } \\
\text { pároco. }\end{array}$ \\
\hline $\begin{array}{l}\text { HOUAISS } \\
(2009)\end{array}$ & $\begin{array}{l}\text { Substantivo masculino. } 1 \text { aquele } \\
\text { que substitui outro; } 2 \text { religioso que, } \\
\text { investido dos poderes de outro, exerce } \\
\text { em seu nome suas funções; } 2.1 \text { padre } \\
\text { que faz as vezes de prelado; } 2.2 \\
\text { padre que substitui o pároco de uma } \\
\text { paróquia; } 3 \text { irmão que, nas confrarias, } \\
\text { faz as vezes de chefe ou juiz; } 4 \text { Uso: } \\
\text { informal. m. q. pároco }\end{array}$ & $\begin{array}{l}\text { Lat. vicarium, } i \text { “o } \\
\text { que faz as vezes de } \\
\text { outro, substituto". }\end{array}$ & Padre, irmão. \\
\hline
\end{tabular}




\subsection{Capelão}

Em todas as obras consultadas, o item capelão possui a acepção de religioso que tem por incumbência o cuidado de uma capela, que é, geralmente, uma igreja menor e/ou particular.

Quadro 3 - Ficha do item lexical capelão

\begin{tabular}{|c|c|c|c|}
\hline Obra & Definição & Etimologia & $\begin{array}{l}\text { Itens } \\
\text { lexicais } \\
\text { afins }\end{array}$ \\
\hline $\begin{array}{l}\text { BLUTEAU } \\
(1728, \text { p.122- } \\
123, \text { v.2) }\end{array}$ & $\begin{array}{l}\text { Capellam, Capellaõ. O Sacerdote assala- } \\
\text { riado que tem obrigação de dizer Missa } \\
\text { em Oratorio, ou Igreja. Sacerdos ad rem } \\
\text { divinam in sacello faciendam constitu- } \\
\text { tus. Capellaõ, que tem cuidado da Ca- } \\
\text { pella de alguem. Alicujas sacello pra- } \\
\text { fectus, ou alicui a sacello. Capellaõ mór. } \\
\text { Dignidade na Capella Real, a tomàraõ os } \\
\text { Reys de Portugal dos Reys Suecos, seus } \\
\text { antecessores; e naõ he pequena honra } \\
\text { para os Capellaẽs móres deste Reyno o } \\
\text { serem successores de S. Martinho, que } \\
\text { foi o primeiro, que teve esta dignidade, } \\
\text { e o Bispado de Dume, a quem era anne- } \\
\text { xa. Monarc. Lufit. tom. 2. fol. 196. Por } \\
\text { excusar termos Gentilicos, como Sacri- } \\
\text { ficulos, e palavras Gregas, que poucos } \\
\text { entendem, como, Hierophanta, que he } \\
\text { o mesmo, que Sacrorum antistes; enten- } \\
\text { do, que melhor seria usar das palavras, } \\
\text { Sacellanus, ou Capellanus, porque saõ } \\
\text { derivadas de Sacellum, e de Capella, } \tilde{\text { q }} \\
\text { saõ palavras Latinas. Capellaõ. Titulo de } \\
\text { cortesania, como quando dizem Frades, } \\
\text { ou Clerigos Capellaõ de v.m. }\end{array}$ & $\begin{array}{l}\text { Saõ derivadas de } \\
\text { Sacellum, e de } \\
\text { Capella, ̃ saõ } \\
\text { palavras Latinas }\end{array}$ & Frade, clérigo. \\
\hline $\begin{array}{l}\text { SILVA } \\
(1813)\end{array}$ & $\begin{array}{l}\text { Capellão, s.m. Clerigo, que faz os } \\
\text { Officios Divinos de alguma Capella; } \\
\text { e assim se chamão os que recitão } \\
\text { nos córos das Igrejas. § Capellão } \\
\text { mór; há um na Capella Real, e hoje } \\
\text { é o Patriarcha de Lisboa. § Capellães } \\
\text { dos Judeos; os que são sacerdotes nas } \\
\text { Synagogas. }\end{array}$ & Não apresenta. & $\begin{array}{l}\text { Clérigo, } \\
\text { sacerdote. }\end{array}$ \\
\hline
\end{tabular}

(Continua) 
(Conclusão)

\begin{tabular}{|c|c|c|c|}
\hline $\begin{array}{l}\text { BUENO } \\
(1974, \text { p.613) }\end{array}$ & $\begin{array}{l}\text { Sacerdote encarregado de uma capela, } \\
\text { que tem uma capelania. }\end{array}$ & $\begin{array}{l}\text { Lat. med. cap- } \\
\text { pellanus, de } \\
\text { cappella }+ \text { anus, } \\
\text { o encarregado } \\
\text { de guardar a } \\
\text { relíquia de } \mathrm{S} \text {. } \\
\text { Martinho. }\end{array}$ & Sacerdote. \\
\hline $\begin{array}{l}\text { CUNHA } \\
(2010, \text { p.124) }\end{array}$ & $\begin{array}{l}\text { Cargo, dignidade ou benefícios de } \\
\text { capelão. }\end{array}$ & $\begin{array}{l}\text { Capellan, XIII, } \\
\text { capellam, XIII. Do } \\
\text { antigo provençal } \\
\text { capelan, derivado } \\
\text { do baixo latim } \\
\text { cappellamus. }\end{array}$ & .. \\
\hline $\begin{array}{l}\text { HOUAISS } \\
(2009)\end{array}$ & $\begin{array}{l}\text { Substantivo masculino. } 1 \text {. sacerdote res- } \\
\text { ponsável pelos ofícios religiosos de uma } \\
\text { capela; } 1.1 \text { sacerdote encarregado de ca- } \\
\text { pela particular e, como tal, esp. importante } \\
\text { para a família ou comunidade à qual essa } \\
\text { capela pertence; } 2 \text {. Regionalismo: Brasil. } \\
\text { Uso (informal): Macaco velho e esperto } \\
\text { que serve de guia para os outros do bando; } \\
\text { padre-mestre; } 3 \text {. Regionalismo (São Pau- } \\
\text { lo): aquele que puxa orações. }\end{array}$ & $\begin{array}{l}\text { Datação: } 1153 \text {. } \\
\text { Do provençal } \\
\text { capelan e, este, } \\
\text { do latim medie- } \\
\text { val cappellanus } \\
\text { (i/'’id'), derivado } \\
\text { de cappella (ae), } \\
\text { diminutivo de } \\
\text { cappa. }\end{array}$ & $\begin{array}{l}\text { Sacerdote, } \\
\text { padre-mestre. }\end{array}$ \\
\hline
\end{tabular}

\subsection{Sacerdote}

O sacerdote possui um sentido marcado pelo zelo pastoral e pela honra. Os sacerdotes eram e são até hoje os responsáveis pela oferta de sacrifícios a Deus - se levarmos em consideração os preceitos da Igreja Católica pelos quais o sacerdote rememora/atualiza o sacrifício da paixão de Cristo. 
Quadro 4-Ficha do item lexical sacerdote

\begin{tabular}{|c|c|c|c|}
\hline Obra & Definição & Etimologia & $\begin{array}{c}\text { Itens lexicais } \\
\text { afins }\end{array}$ \\
\hline $\begin{array}{l}\text { BLUTEAU } \\
(1728, \mathrm{p} .419, \\
\text { v.7) }\end{array}$ & $\begin{array}{l}\text { Este nome, respectivamente a Deos, } \\
\text { val o mesmo que Sacrificador; e } \\
\text { respectivamenteaoshomens, significa } \\
\text { o mesmo que em Latim Sacradans, } \\
\text { ou Sacradocens, ou Sacra dos; e de } \\
\text { todos estes significados se argue, } \\
\text { que o Sacerdote ha de ser totalmente } \\
\text { consagrado a Deos, para lhe offerecer } \\
\text { sacrificios, e juntamente sacrificado } \\
\text { ao povo, para lhe administrar os } \\
\text { Sacramentos, e para o ajudarem } \\
\text { todas as materias, concernẽtes à } \\
\text { salvação de sua alma. [...] Fazião } \\
\text { os Egypcios dos seus Sacerdotes os } \\
\text { seus Reys; e a todos os seus Filosofos } \\
\text { davaõ o mesmo titulo. Entre os } \\
\text { Indios, o Sacerdocio he hereditario, } \\
\text { como antigamente o era entre os } \\
\text { Hebreos; o filho de hum Bramane } \\
\text { he Sacerdote, e casa com a filha de } \\
\text { outro Bramane. Sacedote entre os } \\
\text { Christãos he o mesmo que Clerigo } \\
\text { de Missa. Os Sacerdotes Hebreos, q́ } \\
\text { sacreificavãm boys, cordeyros, ec. } \\
\text { erão figura dos Sacerdotes da ley } \\
\text { da Graça, que no sacrificio do Altar } \\
\text { offerecem ao Eterno Pay o Divino } \\
\text { Cordeyro. Sacerdos, otis. Masc. }\end{array}$ & $\begin{array}{l}\text { Significa o mesmo } \\
\text { que em Latim } \\
\text { Sacradans. }\end{array}$ & $\begin{array}{l}\text { Sacrificador, rei, } \\
\text { filósofo, clérigo de } \\
\text { missa. }\end{array}$ \\
\hline $\begin{array}{l}\text { SILVA } \\
(1813)\end{array}$ & $\begin{array}{l}\text { Sacrificador Gentilico; o que faz, } \\
\text { ou ministra aos Sacrificios do } \\
\text { verdadeiro Deus, e são de ordens } \\
\text { menores, ou maiores, e Presby- } \\
\text { teros. }\end{array}$ & Não apresenta. & $\begin{array}{l}\text { Sacrificador, } \\
\text { presbitero. }\end{array}$ \\
\hline
\end{tabular}


(Conclusão)

\begin{tabular}{|c|c|c|c|}
\hline $\begin{array}{l}\text { BUENO } \\
(1974, \text { p.3607) }\end{array}$ & $\begin{array}{l}\text { Ministro religioso, padre, eclesi- } \\
\text { ástico revestido de ordens sacras. }\end{array}$ & $\begin{array}{l}\text { Lat. sacerdos, sa- } \\
\text { cerdotis, derivado } \\
\text { de sacer, sagrado } \\
\text { e o tema indo- } \\
\text { europeu tho-ts, } \\
\text { raiz dh, fazer: } \\
\text { aquele que faz } \\
\text { coisas sagradas. }\end{array}$ & $\begin{array}{l}\text { Ministro religioso, } \\
\text { padre, sacerdote, } \\
\text { vigário. }\end{array}$ \\
\hline $\begin{array}{l}\text { CUNHA } \\
(2010, \text { p.574) }\end{array}$ & $\begin{array}{l}\text { Entre os antigos, aquele que tra- } \\
\text { tava dos assuntos religiosos e } \\
\text { tinha o poder de oferecer vítimas } \\
\text { à divindade. Ministro do culto } \\
\text { divino. }\end{array}$ & $\begin{array}{l}\text { XIII, do latim } \\
\text { sacerdōs }(-\bar{o} t i s)\end{array}$ & $\begin{array}{l}\text { Ministro do culto } \\
\text { divino. }\end{array}$ \\
\hline $\begin{array}{l}\text { HOUAISS } \\
(2009)\end{array}$ & $\begin{array}{l}\text { Substantivo masculino. } 1 \text { sacrifi- } \\
\text { cador, aquele que oferecia vítimas } \\
\text { à divindade, entre os povos } \\
\text { antigos. } 2 \text { aquele que recebeu as } \\
\text { ordens sacerdotais e que ministra } \\
\text { os sacramentos da Igreja; padre. } \\
3 \text { Derivação: sentido figurado. } \\
\text { Aquele que exerce profissão } \\
\text { honrosa e elevada ou missão nobre. }\end{array}$ & $\begin{array}{l}\text { Datação: século } \\
\text { XIII. Do latim sa- } \\
\text { cerdos (ótis). Lit: } \\
\text { "aquele a quem } \\
\text { cabe o desem- } \\
\text { penho das cer- } \\
\text { imônias sagradas; } \\
\text { sacerdote, padre". }\end{array}$ & Sacrificador, padre. \\
\hline
\end{tabular}

\subsection{Pároco}

Nas definições e nas etimologias apresentadas para a palavra pároco, se faz muito presente a figura de um administrador. Os párocos possuem como ofício a gestão e a condução de uma paróquia. A paróquia ou freguesia não se limita a uma igreja, mas a uma porção de terra de uma determinada diocese. 
Quadro 5 - Ficha do item lexical pároco

\begin{tabular}{|c|c|}
\hline Obra & Definição \\
\hline $\begin{array}{l}\text { BLUTEAU } \\
(1728, \\
\text { p.280, v.6) }\end{array}$ & $\begin{array}{l}\text { Pârroco. Parochus, i. Masc. vid. } \\
\text { Cura. Parochus he palavra Latina, } \\
\text { ou (para melhor dizer) latinizada } \\
\text { do Grego. Della usa Horacio, e } \\
\text { outros antigos Authores. Entre os } \\
\text { Romanos significava o mesmo que } \\
\text { Provedor, distribuidor. E Parochus } \\
\text { era aquelle, que tinha a seu cargo } \\
\text { dar lenha, e sal aos que o Senado } \\
\text { mandava às Provincias para } \\
\text { negocios publicos. Parroco pois na } \\
\text { Christandade tambem he aquele, } \\
\text { que distribue, e administra aos } \\
\text { freguezes os Sacremẽtos da Igreja, } \\
\text { e particularmente aos moribundos, } \\
\text { que estão para passar para a outra } \\
\text { vida, o Viatico. Vid. Parrochia. } \\
\text { Os Parrochos saõ os Confessores } \\
\text { ordinarios, etc. Mon. Lusit. tom. 5. } \\
\text { fol. } 73 \text {. col. 4). }\end{array}$ \\
\hline
\end{tabular}

SILVA O Cura d'almas de alguma Não apresenta. Curad'almas.

(1813) Freguezia, ou Parochia.

BUENO Padre, sacerdote que tem a seu

Lat. crist. paro- Padre,

p.2893)

confunde-se com vigário.

chus, gr. parokhos, sacerdote,

empregado do go- vigário.

verno que cuidava

do necessário

nas viagens dos

hóspedes oficiais, do verbo parekô, providencio.

CUNHA Sacerdote encarregado de uma Do latimparŏchus (2010, paróquia, vigário.

(-ĩ), derivado do

Sacerdote, vigário. grego párochos. 
(Conclusão)

$\begin{array}{llll}\text { HOUAISS } & \text { Substantivo masculino. Padre res- } & \text { Datação: 1710. } & \text { Padre, vigário, } \\ \text { (2009) } & \text { ponsável por uma paróquia; vi- } & \text { Do latim paròchus } \\ \text { gário, padre-cura. } & \text { (i) "fornecedor de } & \\ & & \text { víveres aos que } \\ & \text { viajam em serviço } \\ & \text { público". }\end{array}$

\subsection{Clérigo}

\section{O termo clérigo parece abarcar todos os outros termos, principalmente o de sacerdote.}

Quadro 6-Ficha do item lexical clérigo

\begin{tabular}{|c|c|}
\hline Obra & Definição \\
\hline $\begin{array}{l}\text { BLUTEAU } \\
(1728, \\
\text { p.342, v.2) }\end{array}$ & $\begin{array}{l}\text { [...] Oprimeiro uso do nome Clerici } \\
\text { se estendeo a todos que exerciaõ } \\
\text { na Igreja algum ministerio, et } \\
\text { segundo Sancto Isidoro chegava } \\
\text { este a nove graos, a saber, Ostiario, } \\
\text { Psalmista, Leitor, Exorcista, } \\
\text { Acolito, Subdiacono, Diacono, } \\
\text { Presbitero, Bispo [...] Por muytos } \\
\text { capitulos de Direyto, Concilios } \\
\text { e Escrituras de seculares, Os } \\
\text { Monges ou Frades como parte } \\
\text { da Jerarchia Ecclesiastica tiveraõ } \\
\text { o mesmo nome, Clericorum } \\
\text { nomine [...]. Tambem Conegos, } \\
\text { particularmente Regrantes que } \\
\text { serviaõ nas Igrejas Cathedraes } \\
\text { foram chamados Clerici. [...] et } \\
\text { porque as letras são necessárias } \\
\text { aos que servem a Deos et ao } \\
\text { próximo na Igreja, a todo homem } \\
\text { letrado, et douto se deu o nome de } \\
\text { Clericus [...] Finalmente a todo o } \\
\text { fiel Christaõ, assi Secular como } \\
\text { Ecclesiastico, compete o nome de } \\
\text { Clerigo [...]. Entre nós Clerigo é } \\
\text { Synonimo de Sacerdote. Clerigo } \\
\text { de Missa. Sacerdos, otis. Masc. } \\
\text { Vid. Sacerdóte. }\end{array}$ \\
\hline
\end{tabular}

\author{
Itens lexicais \\ afins \\ ta, Leitor, Exor- \\ cista, Acolito, Sub- \\ diacono, Diacono, \\ Presbitero, Bispo; \\ Sacerdote; clérigo \\ de missa.
}

Derivase do Grego Ostiario, Psalmis-

Cliros, que quer 
(Conclusão)

SILVA

(1813)
CLÉRIGO, s. m. Homem chamado para a Igreja e para os ministérios da religião; Sacerdote, Secular, ou Regular. [...]

BUENO Clérigo - adj. Que pertence ao clero. ( 1974 , Clero-s. m. A classe sacerdotal. p.743) O conjunto dos eclesiásticos da Igreja Católica.

CUNHA clérigo sm. "aquele que tem to( $\begin{array}{llll}2 & 0 & 1 & 0\end{array}$, das as ordens sacras, ou algumas p.156) delas" "sacerdote cristão" XIII. Do lat. tard. clericus, deriv. do gr. klerikós.

HOUAISS Substantivo masculino. 1 indi(2009) víduo que pertence à classe eclesiástica; 2 aquele que recebeu todas ou algumas das ordens sacras; 3 sacerdote cristão; 4 aquele que recebeu a tonsura.

\subsection{Cura}

O item lexical cura pode ser compreendido, nas obras consultadas, como aquele religioso encarregado do cuidado, da instrução e da cura espiritual dos fiéis de uma determinada comunidade. Essa ideia é presente quando analisamos os itens lexicais afins.

Lat. clericus; Classe sacerdotal;

Lat. crist. cleros, conjunto dos ecledo gr. kleros [...] siásticos (no caso

Do lat. tard. cler- Sacerdote cristão. icus $<$ gr. klerikós Lat. ecl. clericus, i "membro da clerezia", por via popular.
Sacerdote, sacerdote cristão. de clero)

\section{Clerigo del-Rei: \\ Ecclesiastico}


Quadro 7 - Ficha do item lexical cura

\begin{tabular}{|c|c|c|c|}
\hline Obra & Definição & Etimologia & $\begin{array}{c}\text { Itens lexicais } \\
\text { afins }\end{array}$ \\
\hline $\begin{array}{l}\text { BLUTEAU } \\
(1728, \\
\text { p.639, v.2) }\end{array}$ & $\begin{array}{l}\text { Cura. Parocho. Derivase de Curatus, } \\
\text { que em Authores da baxa Latinidade } \\
\text { se acha por Curater [...]. Segundo o } \\
\text { Mestre Venegas, Cura se chama em } \\
\text { Romance o Pastor de huma Igreja, } \\
\text { porque naõ basta, que seja cuydadoso, } \\
\text { se naõ Cura, que em Latim significa o } \\
\text { Proprio cuydado. No liv. 2. cap. } 8 \text { da } \\
\text { Vida de S. Francisco Xavier chama } \\
\text { Tursellino ao Cura, Curaio, onis. } \\
\text { Masc. alludindo ao antigo officio de } \\
\text { Craio, que os antigos Romanos davaõ } \\
\text { ao Sacerdote, ou sacrificadôr de cada } \\
\text { curia. Tendo Romulo dividido o povo } \\
\text { Romano em tres Tribus, e em trinta } \\
\text { curias, mandou que tivesse cada curia } \\
\text { seu Templo com seus sacrificios, } \\
\text { com suas festas, e ordenou, que cada } \\
\text { Templo em particular fosse governado } \\
\text { por um ministro, ou sacrificadôr, } \\
\text { chamado curio, e assi havia trinta } \\
\text { curioens, que presidiaõ nas trinta } \\
\text { curias, e recebiaõ as Ordens do curiaõ } \\
\text { mór. Tambem chama Turfellino ao } \\
\text { cura, Parochus, i. Masc. Paraeciae } \\
\text { curator, e Parochiae praepositus. } \\
\text { Segundo Q Mario Corrado, lib. } 5 \text {. } \\
\text { de Cop. Serm. Lat. tambem poderás } \\
\text { chamar ao cura curialis flamen. Duv. } \\
\text { do, que dem os Criticos licença a } \\
\text { Boldonio para introduzir, Curionatus, } \\
\text { por Officio de Cura, Sicut a Consule } \\
\text { consulatus, ita à Curione curionatus, } \\
\text { na sua Epigraphica, pag. } 134 \text { e na pag. } \\
\text { 135. quer que as funçoens do cura se } \\
\text { posso chamar curionia. [...] }\end{array}$ & $\begin{array}{l}\text { Em Latim sig- } \\
\text { nifica o Proprio } \\
\text { cuydado }\end{array}$ & $\begin{array}{l}\text { Pároco, pastor, } \\
\text { sacerdote, sac- } \\
\text { rificador, min- } \\
\text { istro. }\end{array}$ \\
\hline
\end{tabular}


(Conclusão)

\begin{tabular}{|c|c|c|c|}
\hline $\begin{array}{l}\text { SILVA } \\
(1813)\end{array}$ & $\begin{array}{l}\text { O Sacerdote, cuja igreja tem } \\
\text { fregueses, que elle é obrigado a } \\
\text { curar, ou doutrinar, e Sacramentar, } \\
\text { neste sentido é masc. "o Cura da } \\
\text { Freguezia." }\end{array}$ & Não apresenta. & Sacerdote. \\
\hline $\begin{array}{l}\text { BUENO } \\
(1974, \\
\text { p.866) }\end{array}$ & $\begin{array}{l}\text { Pároco, vigário, padre que tem a seu } \\
\text { cargo o cuidado das almas. }\end{array}$ & $\begin{array}{l}\text { Lat. ecles. cura. } \\
\text { C o m p o s t o. } \\
\text { sinecura, ofício, } \\
\text { emprego, sem o } \\
\text { cargo espiritual } \\
\text { das almas. Lat. } \\
\text { sine cura. }\end{array}$ & $\begin{array}{l}\text { Pároco, } \\
\text { vigário, padre. }\end{array}$ \\
\hline $\begin{array}{l}\text { CUNHA } \\
(2010 \\
\text { p.195) }\end{array}$ & $\begin{array}{l}\text { Antiga paróquia, XIII; sacerdote, } \\
\text { XIV. }\end{array}$ & Do latim cūra. & Sacerdote. \\
\hline $\begin{array}{l}\text { HOUAISS } \\
(2009)\end{array}$ & $\begin{array}{l}\text { Substantivo masculino. Pároco, vi- } \\
\text { gário de freguesia, povoação, aldeia. } \\
\text { Ex.: o cura era o saber e a moralidade } \\
\text { do lugar. }\end{array}$ & $\begin{array}{l}\text { Datação: sécu- } \\
\text { lo XIII. Do la- } \\
\text { tim, cúra (ae) } \\
\text { "cuidado, admi- } \\
\text { nistração etc." }\end{array}$ & $\begin{array}{l}\text { Pároco, } \\
\text { vigário. }\end{array}$ \\
\hline
\end{tabular}

\section{Considerações finais}

Com esta investigação, foi possível fazer um levantamento lexicográfico dos itens lexicais capelão, clérigo, cura, padre, pároco, sacerdote e vigário na língua portuguesa das Minas Gerais do século XVIII. O percurso dessas palavras ao longo do tempo, muitas vezes, não é claro. O certo é que todos esses itens possuem percursos que se entrecruzam, sobretudo porque dizem respeito ao mesmo referente no mundo. Quando há diferença desse referente, ela se manifesta apenas em algumas nuances. $\mathrm{O}$ ato de nomear é um complexo processo fundador e sustentador da linguagem, por meio do qual se fabrica o mundo. Já de antemão, salientamos que, por esse ponto de vista, não são nítidas as fronteiras que separam a realidade extralinguística daquela que é concebida pela própria língua, uma vez que, não raro, uma se sobrepõe à outra. Como efeito, é uma ilusão o vínculo aparentemente forte que as palavras mantêm com as coisas. 
Vale salientar também que as nomeações aqui estudadas são atravessadas por fortes relações histórico-sociais existentes no Período Colonial mineiro. Parte dessas relações podem ser observadas na afirmação de Santos, Seabra e Costa (2017), de que, ao longo dos períodos Colonial e Joanino, nas Minas Gerais, "[o]s nomes dos acidentes, referentes à Capitania e às Comarcas mineiras correspondem aos assentamentos da população, relativos à expressão das hierarquias político-administrativas e eclesiásticas das povoações que se encontravam vigentes nos períodos estudados."

Ao lado dos itens aqui analisados, apareceram outros, alguns com um maior compartilhamento de traços referenciais, outros nem tanto: confessor, diácono, diretor da consciência, distribuidor, filósofo, frade, mestre espiritual, ministro, ministro do culto divino, padre-cura, padremestre, pai, papa, pastor, prelado, presbitero, provedor, rei, sacerdote católico, sacrificador, senador romano etc. Todos esses termos servem para designar uma figura masculina que, por meio de alguns votos, geralmente religiosos, passa a liderar um determinado grupo de fiéis.

Algumas etimologias e datações aqui apresentadas podem ser questionadas, quando o autor da obra lexicográfica não fornece detalhes da fonte de determinada informação. Datar uma palavra como sendo do século XIII, como apresentado em alguns exemplos deste trabalho, é muito arriscado pela margem temporal e pela ausência de textos que comprovem isso. $\mathrm{Na}$ área da etimologia, há muito por se fazer, sobretudo para os séculos XVII, XVIII e o XX. O certo é que muitas pessoas, leigas e alguns estudiosos, se sentem aptas para fornecer elementos da história de uma determinada palavra, mas poucos querem se debruçar sobre o extenso volume de textos antigos, a maioria deteriorados pelo tempo e de difícil leitura. É preciso voltar-se para os textos e, só assim, será possível fazer "o melhor uso de maus dados" como assevera Labov (1982, p.45).

Não há dúvida de que é necessário expandir a pesquisa: verificar a possível existência de outras palavras utilizadas para fazer referência ao religioso ordenado católico, aumentar o corpus com mais edições fidedignas e torná-lo mais variado diatopicamente, com documentos. Concebemos a discussão deste artigo como um primeiro passo para que se perfaçam os percursos etimológicos dos itens aqui abordados. Em investigações futuras, pretendemos contemplar análises dos usos dos itens lexicais levando-se em conta os contextos linguístico e referencial nos 
quais eles surgem, além da comparação dos termos com seus correlatos de séculos diferentes.

\section{Agradecimentos}

Agradecimentos à professora doutora Maria Cândida Trindade Costa de Seabra, pela leitura crítica do texto inicial. Entretanto, destacamos, é claro, que quaisquer falhas deste texto são de nossa inteira responsabilidade.

\section{Referências}

ÁlVAREZ DE LA GRANJA, M.; BOULLÓN AGRELO, A. I. Dicionario de dicionarios do galego medieval. Coordenação de Ernesto González Seoane. Santiago de Compostela: Instituto de la lengua galega, 2006. Disponível em: <http://sli.uvigo.es/DDGM/index.html>. Acesso em: 1 maio 2018.

BLUTEAU, R. Vocabulario portuguez \& latino. Coimbra: Collegio das Artes da Companhia de Jesus, 1712-1728. 8 v. Disponível em: $<$ http://dicionarios. bbm.usp.br/pt-br/dicionario/edicao/1>. Acesso em: 25 maio 2018.

BUENO, F. da S. Grande dicionário etimológico-prosódico da língua portuguesa: vocábulos, expressões da língua geral e cientifica-sinônimos; contribuições do tupi-guarani. Santos; São Paulo: Ed. Brasília, 1974. 9 v.

CATECISMO da Igreja Católica. São Paulo: Loyola, Vozes, 1993. Não paginado.

CUNHA, A. G. da. (Coord.). Dicionário etimológico da língua portuguesa. Rio de Janeiro: Lexikon, 2010.

DAPENA, J. A. P. Manual de técnica lexicográfica. Madrid: Arco, Libros, 2002.

DUCHOWNY, A. T.; COELHO, S. (Org.). Edição semidiplomática e fac-similar de documentos adamantinos setecentistas. Belo Horizonte: FALE/UFMG, 2013. (Edições Viva Voz).

HALLIG, R.; WARTBURG, W. von. Begriffssystem als grundlage für die lexikographie; Versuch eines Ordnungsschemas. Neu bearbeitete und erweiterte Auflage. Berlin: Akademie Verlag, 1963. 
HOUAISS, A.; VILLAR, M. S. Dicionário eletrônico Houaiss da língua portuguesa. Rio de Janeiro: Editora Objetiva, 2009. Não paginado. 1 CD-ROM.

LABOV, W. Building on Empirical Foundations. In: LEHMANN, W.; MALKIEL, Y. (Org.). Perspectives on Historical Linguistics. Amsterdam, Philadelphia: John Benjamins, 1982. p. 17-92. Doi: https:// doi.org/10.1075/cilt.24.06lab

MALKIEL, Y. Etimología. Madrid: Cátedra, 1996.

MURAKAWA, C. de A. A. António de Morais Silva: lexicógrafo da língua portuguesa. Araraquara: Editora Cultura Acadêmica, 2006.

MURAKAWA, C. de A. A. Raphael Bluteau: marco na lexicografia portuguesa de setecentos. In: MURAKAWA, C. de A.A.; GONÇALVES, M. F. (Org.). Novas contribuições para o estudo da história e da historiografia da língua portuguesa. Araraquara: FCL-UNESP, Laboratório Editorial; São Paulo: Cultura Acadêmica, 2007. p. 159-188.

SALVIANO, B. N. Um estudo etimológico da lexia "surdo": a aproximação da língua a fatos sócio-históricos. In: DUCHOWNY, A. T. (Org.). Pelas veredas da etimologia. São Paulo: NEHiLP/FFLCH/USP, 2016. v. 1. p. 79-89. Disponível em: <http://www.usp.br/nehilp/livros/ Veredas.pdf $>$. Acesso em: 16 abr. 2018.

SANTANA, M. S. Contribuições ao Dicionário etimológico da língua portuguesa, de Antônio Geraldo da Cunha.Domínios de Lingu@gem, Uberlândia, MG, v. 5, n. 2, p. 137-148, 2011. Disponível em: <http://www. seer.ufu.br/index.php/dominiosdelinguagem/article/view/13707/8170>. Acesso em: 30 maio 2018.

SANTOS, M. M. D. dos; SEABRA, M. C. T. C. de; COSTA, A. G. (Org.). Toponímia histórica de Minas Gerais: do Setecentos ao Oitocentos joanino - registros em mapas da Capitania e das Comarcas. Belo Horizonte: MHNJB/UFMG, IHG-MG, 2017. Não paginado. Disponível em: $<\mathrm{http}: / /$ repositoriotoponimia.com.br> . Acesso em: 30 maio 2018.

SEABRA, M. C. T. C. de. A formação e a fixação da língua portuguesa em Minas Gerais: a toponímia da Região do Carmo. 2004. 368 f. Tese (Doutorado em Linguística) - Faculdade de Letras, Universidade Federal de Minas Gerais, Belo Horizonte, 2004. Disponível em: <http://www. bibliotecadigital.ufmg.br/dspace/handle/1843/ALDR-64KQ9A>. Acesso em: 28 maio 2018. 
SILVA, A. de M. Diccionario da lingua portugueza composto pelo padre D. Rafael Bluteau: reformado, e accrescentado por Antonio de Moraes Silva natural do Rio de Janeiro. Lisboa: Officina de Simão Thaddeo Ferreira, 1789. Não paginado. Disponível em: <http://purl.pt/29264/4/>. Acesso em: 25 maio 2018.

SILVA, A. de M. Diccionario da lingua portugueza: recompilado dos vocabularios impressos ate agora, e nesta segunda edição novamente emendado e muito acrescentado, por Antonio de Moraes Silva. Lisboa: Typographia Lacerdina, 1813. Não paginado. Disponível em: $<$ http://dicionarios.bbm.usp. br/pt-br/dicionario/edicao/2>. Acesso em: 25 maio 2018.

SILVA, M. de O.; XAVIER, V. R. D.; PAULA, M. H. de. Descrição e análise de termos eclesiásticos em manuscritos goianos dos séculos XVIII e XIX: uma intersecção entre filologia e terminologia. Raido, Dourados, SP, v. 10, n. 24, 2016. p. 53-64. Disponível em: <http://ojs.ufgd.edu.br/ index.php/Raido/article/view/4918>. Acesso em: 5 jun. 2018.

TORRINHA, F. Dicionário latino português. Porto: Gráficos Reunidos, 1942.

TRIER, J. Der deutsche Wortschatz im Sinnbezirk des Verstandes. Heidelberg: C. Winter, 1931.

VIARO, M. E. A retrodatação automática no projeto DELPo. Trabalho apresentado no III Encontro sobre a Diversidade Linguística em Minas Gerais, realizado em Belo Horizonte, na Universidade Federal de Minas Gerais, em 2017. Comunicação oral. Não publicado.

VIARO, M. E. Etimologia. São Paulo: Contexto, 2011.

Recebido em: 5 de junho de 2018. Aprovado em: 8 de agosto de 2018. 